\title{
Suzuki-Miyaura Coupling Reaction Using Palladium Nanoparticles Immobilized on SPB
}

palladium

Suzuki-Miyaura coupling

Heck reaction

nanoparticles

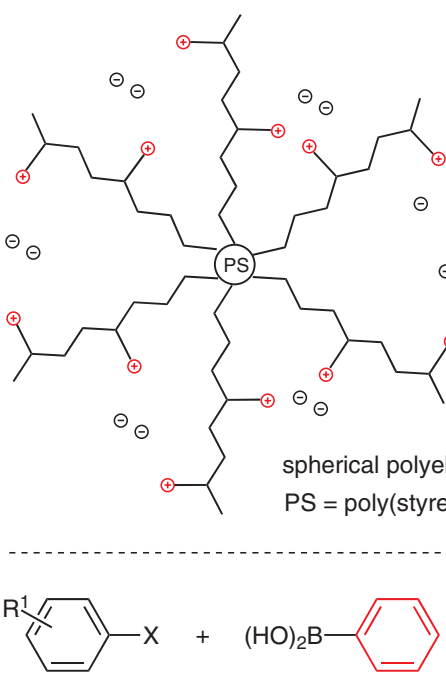

$\mathrm{X}=\mathrm{Br}, \mathrm{R}^{1}=4-\mathrm{Me} ; 83 \%$ yield $\mathrm{X}=\mathrm{Br}, \mathrm{R}^{1}=4-\mathrm{MeO} ; 79 \%$ yield $\mathrm{X}=\mathrm{Br}, \mathrm{R}^{1}=3-\mathrm{NO}_{2} ; 50 \%$ yield

$\mathrm{X}=\mathrm{Br}, \mathrm{R}^{1}=4-\mathrm{NO}_{2} ; 94 \%$ yield $\mathrm{X}=\mathrm{Br}, \mathrm{R}^{1}=4-\mathrm{CF}_{3} ; 89 \%$ yield

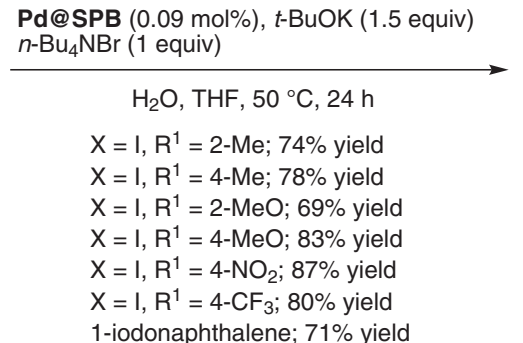

Pd@SPB ( 0.09 mol\%), $t$-BuOK ( 1.5 equiv)

$\mathrm{H}_{2} \mathrm{O}, \mathrm{THF}, 50^{\circ} \mathrm{C}, 24 \mathrm{~h}$

$X=I, R^{1}=2-M e ; 74 \%$ yield $X=I, R^{1}=4-M e ; 78 \%$ yield

II, $\mathrm{R}^{1}=4-\mathrm{NO}_{2} ; 87 \%$ yield

1 -iodonaphthalene; $71 \%$ yield

\section{$\Theta=\mathrm{Cl}^{-}$}

Significance: Palladium nanoparticles immobilized on spherical polyelectrolyte brushes (Pd@SPB) were synthesized and found to promote the Suzuki-Miyaura cross-coupling reaction. Thus, the spherical polyelectrolyte brushes having the (2-methylpropenyloxyethyl)trimethylammonium cation were prepared according to the reported procedures (Y. Mei, G. Sharma, Y. Lu, M. Ballauff Langmuir 2005, 21, 12229). The reaction of SPB with $\mathrm{Na}_{2} \mathrm{PdCl}_{4}$ followed by reduction with $\mathrm{NaBH}_{4}$ gave the palladium nanoparticles immobilized in the SPB matrix (Pd@SPB). The SuzukiMiyaura coupling reaction of aryl halides with phenylboronic acid was carried out in the presence of Pd@SPB (0.09 mol\% Pd) in $\mathrm{H}_{2} \mathrm{O}-\mathrm{THF}$ to give the corresponding biphenyls in good yield (14 examples, 50-94\% yield).
Comment: Recently, the authors have reported the preparation of platinum nanoparticles immobilized on SPB (Pt@SPB), which was found to be an effective catalyst for the reduction of $p$-nitrophenol with $\mathrm{NaBH}_{4}$. The present report described that the palladium nanoparticles (Pd@SPB) exhibited good activity for the Suzuki-Miyaura coupling reaction. This catalyst was recovered and reused for four times without any loss of catalytic activity. Heck reaction using the palladium nanoparticles (Pd@SPB) was also described. 